\title{
Diversity as a Policy Goal: The Case of Television
}

\author{
RONALD D. BRUNNER and KAN CHEN
}

The University of Michigan, Ann Arbor, MI 48109

\begin{abstract}
Diversity in communications is most appropriately understood as a free flow of ideas. In order to implement diversity, a comprehensive model of the communication process must be used for policy research, so that the various participants in the process can be properly restrained from abridging the free flow of ideas. The setting of priorities for implementing diversity has been illustrated using available studies of broadcast and cable television.
\end{abstract}

\section{Introduction}

Concepts of diversity as a goal in communications policy research are numerous. Nearly all other propositions about diversity are controversial.

In one approach, diversity is the extent to which programs are distributed across such categories as entertainment, news and public affairs, and education. The significance of these categories is assumed rather than demonstrated. In another approach, diversity increases with the number of channels available. The assumption is that if additional channels become available, they will be programmed and programmed differently. In still another, more philosophical approach, diversity emerges as the result of a logical analysis. Thus our society should strive for a representative diversity of communications on issues. The application of the concept to concrete circumstances is left as an exercise to the reader or listener.

Other approaches turn out to deny the value of diversity as a policy. Thus elite demands for increased diversity in the form of more news, public affairs, and educational programs would reduce the satisfaction of the mass consuming audience if implemented; or the existing distribution of programs is appropriate because it is adapted to audience preferences through audience ratings; or the existing distribution is appropriate because attempts to alter it would be a "cure" worse than the condition in terms of democratic principles. Implicit in these approaches are the assumptions that audience preferences are unaffected by the mix of programs supplied, and that discretionary judgments made by those who supply programs are insignificant if they are acknowledged at all. ${ }^{1}$

\footnotetext{
${ }^{1}$ A number of diversity concepts can be found in a forthcoming special issue of the Journal of Com-
} munication (1978). 
This state of affairs reflects the varied backgrounds of contributors to the debate. Representatives of many academic disciplines, professions, businesses, and government agencies can be identified in the literature. But this state of affairs also reflects the variety of purposes brought to the study of the issue. For some, diversity provides yet another opportunity to exercise the skills acquired in graduate or professional school; for others, it provides an opportunity to shape policy on behalf of public interests (however understood) or private interests; and for still others, diversity serves as a convenient rationalization for policy made on other grounds.

What may appear to be a richness of concepts turns out, on further reflection, to be a maze that hinders the selection of reasonable priorities for policy research. Clarification of these priorities requires a more comprehensive and adaptable conception of diversity: One that could be used to specify the conditions under which the less inclusive concepts are applicable; and one that could be used to bridge the gap between research and policy as events unfold. Our purpose is to propose and illustrate a concept of diversity that meets these requirements, with special emphasis on cable television. The effort will be repaid to the extent that it provides guidance in the task of goal clarification, ${ }^{2}$ for researchers and policy makers alike, in communications and other policy areas.

The special emphasis stems from the promise of cable television as a welcome supplement or alternative to broadcast television among those who charge the latter with a lack of diversity. The prospect of more channels to accommodate more viewpoints, two-way channels, and a host of new communications services is apparent in influential treatments of the subject. For example, the Sloan Commission subtitled its report The Television of Abundance, ${ }^{3}$ and Ralph Lee Smith titled his vision The Wired Nation. ${ }^{4}$ Moreover, the collection of subscriber fees for basic cable service and per program or per channel fees for pay-cable service promises a financial alternative to advertiser support. The emphasis is also appropriate because cable television is presently a less developed and less powerful medium than broadcast television. The possibility is that it can be shaped and regulated better to serve the public interest in the future.

\section{Diversity is Contextual}

\section{Outcomes $^{5}$}

What is potentially at stake in cable television as a supplement or alternative to broadcast television? A quick look at broadcast television provides a rough

\footnotetext{
2 This is one of five logically necessary tasks involved in any policy decision. See Harold D. Lasswell, $A$ Pre-view of Policy Sciences (New York: Elsevier, 1971), Chapter 3. Goal clarification is also a particularly important task in the intelligence and appraisal phases of decision processes. See ibid., pp. 27-33.

3 Sloan Commission on Cable Communications, On the Cable: The Television of Abundance (New York: McGraw-Hill, 1971).

4 Ralph Lee Smith, The Wired Nation: Cable TV: The Electronic Communications Highway (New York: Harper \& Row, 1972).

5 "When he first examines a social process the observer is impressed by the 'seamless web' of life. Nonetheless, some 'seams' must be found if differentiation is to be possible. The most direct device is to select culminating outcomes, that is, events that are generally understood in a given situation to be very desirable (or undesirable) happenings." Lasswell, op. cit., p. 17. (Emphasis in the original.)
} 
understanding of potential social outcomes, and such an understanding turns out to be important in defining diversity.

One answer to the question is that television is a highly profitable industry, with 1975 revenues of about $\$ 4.1$ billion and earnings before federal taxes of about $\$ 780$ million dollars. ${ }^{6}$ But it is only "an averaged-sized industry . . . about the same as such prosaic activities as the manufacture of paperboard boxes, cotton broad-woven fabrics, or canned fruits and vegetables." duces well over a trillion dollars of goods and services, it is quite small. The value to consumers of broadcast television has been estimated at about seven times television revenues. This amounts to about $4 \%$ of after-tax household incomes for the average television household. ${ }^{8}$

Another answer to the question is that television is a major cultural institution distributing words and pictures to virtually all Americans. According to 1969 estimates, men under 35 and boys and girls aged $12-17$ viewed television an average of about 20 hours per week. This is the minimum among age-sex groups. The maximum is 33 hours per week for women over the age of 50 (ibid, p. 24). On the basis of a 168-hour week, this amounts to about 12 to $20 \%$ of the attention of members of American society. On the basis of waking hours per week, the percentages are considerably higher.

But the words and pictures used to deliver an audience to an advertiser have consequences far beyond the public pocketbook and consumer satisfaction. The affluent people, shiny new cars, and slick apartments that grace the screen may reinforce the expectation of prosperity and the consumption ethic among viewers. The counter-culture makes its case for a resource conserving ethic elsewhere. The young, healthy and attractive models who dominate the ads may gratify those who perceive themselves in the same terms. Attention, after all, is the most basic form of respect. Other viewers may feel disrespected and alienated or develop a degree of selfcontempt and self-loathing at their inability to conform to these models. The situation comedy that dramatizes problems generated and resolved by a few people in the space of half an hour may reinforce faith in and a preference for individual action. The thesis of collective responsibility and action in both private and public affairs is more likely to fall on deaf ears. The daytime soap opera may be taken by a housewife as insight into the management of her own affairs and corroboration of their importance relative to other concerns. The detective series that delivers the audience may provide a continuing education in the techniques of wrecking mayhem on other human beings. The news or public affairs program that features a hardhitting interview (reporter takes on politician), blood on the local streets and highways, or a film clip from a distant war may be received as the functional equivalent of a heavy-weight prize fight.

The subjective outcomes of the words and pictures are more difficult to trace than the transfer of dollars from one account to another, and they are complicated by the

${ }^{6}$ Television Factbook Services Volume, 1977 Edition/No. 46 (Washington, D.C.: Television Digest, Inc., 1977), p. 53-a.

7 Roger G. Noll, Merton J. Peck, John J. McGowan, Economic Aspects of Television Regulation (Washington, D.C.: The Brookings Institution, 1973), p. 1.

8 Ibid., p. 23. 
enormously varied predispositions of audience members. But they are more pervasive in their impacts. Television is primarily a communications medium that directly affects the loyalties, beliefs, and preferences of virtually every American. And it affects indirectly the actions contingent on these perspectives. No value in American society remains untouched. To describe television as an average-size industry worth $4 \%$ of average household income is seriously to underestimate its impact. ${ }^{9}$

\section{Diversity as a Goal}

Our cultural tradition leaves little doubt about basic preferences regarding a medium of communication in which the potential for service and for abuse is so great. Freedom of expression and freedom of the press are affirmed as valid goals for all civilized societies. ${ }^{10}$ Freedom of expression and freedom of the press are moral rights because they entail moral obligations. A man burdened with an idea owes it to his own thought and to the good of the community to express it. The duty is discharged and the right retained even if the man is in error, but not if he is deliberately or irresponsibly in error, as in the case of lying. Similarly, the press has an obligation to circulate an idea that processes of free speech have brought to public attention even if those who control the press do not share the idea. The press fails in its duty and forfeits its moral right when it suppresses an idea. Thus freedom from coercion as a right entails freedom for the circulation of ideas as a duty. But there are good reasons to retain legal protection even when the moral right is forfeited. Legal sanctions on abuses of freedom of speech and freedom of the press are limited to only a few recognized areas where "an utterance or publication invades in a serious manner personal rights or vital social interests." Al Among these are libel, misbranding, obscenity, and incitement to riot. The right to protection is backed by the authority of the First Amendment: "Congress shall make no law . . . abridging freedom of speech, or of the press ...",

It is not merely a matter of philosophical or legal niceties. The value of the principles is grounded in the lessons of experience. ${ }^{12}$ First, a free flow of ideas is essential to political liberty. None of the freedoms guaranteed in the Bill of Rights is secure where opinions cannot be freely expressed. And where freedom of expression exists the seeds of a free society and the means of extending it also exist. "Freedom of expression is therefore unique among liberties: it promotes and protects all the rest.", 13 Second, a free flow of ideas is essential in the development of ideas of potential

\footnotetext{
${ }^{9}$ Noll, Peck and McGowan are careful to draw a distinction between the economic and cultural impacts of television, although their priorities are not necessarily the same as ours. They write that ". . . many of the issues of television are cultural or even philosophical. While at times we venture beyond economics in our policy judgments, we do not intend, nor are we competent, to present in this volume the full range of considerations that should determine the role of television in American society." Ibid., pp. 18-19.

10 Commission on Freedom of the Press, A Free and Responsible Press (Chicago: University of Chicago Press, 1947), p. 12.

11 Ibid., p. 11.

12 On the foundations of American values, see Abraham Kaplan, American Ethics and Public Policy (New York: Oxford University Press, 1963), pp. 8-27.

13 Ibid., p. 6.
} 
value to society. Potentially valuable ideas are often first put in crude and indefensible forms; and innovative ideas in any form are likely to arouse resistance among protectors of the status quo. "They need the chance to develop through free criticism as well as the chance to survive on the basis of their ultimate worth." ${ }^{14} \mathrm{An}$ open marketplace of ideas does not suppress conflict but liberates it. The intention is that " the level of social conflict shall be lifted from the plane of violence to the place of discussion." is

The principles are validated by failures of adaption in our own experience. Consider this voice from Watts, recorded in the turmoil of August 1965:

All we wants is that we get our story told, and get it told right! What we do last night, maybe it wasn't right. But ain't nobody come down here and listen to us before. 16

Martin Luther King made the same point when he said that "A riot is the language of the unheard." 17

We propose that diversity in communications, as a goal of a free society, is most appropriately understood as a free flow of ideas. More specifically, it is freedom of expression and freedom of the press. Of course there is nothing new in this: The challenge is to implement the goal. ${ }^{18}$ This requires identifying and restraining those in a position to interfere with a free flow of ideas when they do not restrain themselves; and making sure that such actions do not further abridge the free flow of ideas. (The cure may be worse than the condition.)

When the Bill of Rights was adopted, it was sufficient to guarantee a free flow of ideas that the government restrain itself through compliance with the First Amendment. ${ }^{19}$ Among other things, entry into the publishing business was a relatively feasible option for dissidents who felt they were not being heard; and face-to-face communications played a much more important role in transaction of the public business among the small settlements nestled along the Atlantic Coast. The revolution in communications has changed matters. Protection against government abridgment of the basic rights no longer guarantees a chance to be heard when economic and technical changes have placed direct access beyond the means of all but a relative few. At the same time, public reliance on personal observation and communications has given way to a relative dependence on mass media in an era where the public business takes place on a continental and global scale. The task is to adapt the goal to current circumstances-and to continue to adapt it as the communications revolution continues.

\section{Implementing Diversity}

In order to implement diversity, we need a comprehensive map of the communication process that can be adapted to changing circumstances and to the tasks of

\footnotetext{
14 Ibid.

15 Ibid, p. 113. Emphasis in the original.

16 Nicholas Johnson, How To Talk Back To Your Television Set (New York: Bantam, 1970), p. 93.

17 Ibid.

18 Compare the approach in Phil Jacklin's contribution to the special issue of the Journal of Communication, op. cit.

19 Commission on Freedom of the Press, op. cit., pp. 15-19.
} 
research and policy-making. Communication theory provides a useful model. An inclusive description of an act of communication indicates who says what to whom, how, and with what effect. The terms emphasized direct attention to each part of an act of communication and suggest the kind of analysis specialized to each. These are, respectively, control analysis, content analysis, audience analysis, media analysis, and effect analysis. ${ }^{20}$ This simple model can be used to elaborate the goal of diversity as a free flow of ideas. For example, preferences could be specified with respect to each part of the acts of communication that occur in a given system. Here we shall illustrate the use of the model as a tool in the empirical task of mapping the barriers to diversity in commercial broadcast television and in cable television.

The structure of these media can be summarized in part by listing the relatively stable set of participants who initiate or receive messages (control analysis and audience analysis). These are conventionally referred to as writers, directors, producers, networks, stations or cable systems, and audiences, but of course advertisers, government, and others also participate. The structure can also be summarized in part by noting the relatively stable institutions through which these participants interact (media analysis). For example, each of the three television networks owns five television stations and is affiliated with many others by contract. Cable television has a number of multiple system owners (MSO's), some of which contract with networks for pay-cable services. The government establishes a regulatory and statutory framework. And technology is also important in media analysis. Networks are able to distribute programs simultaneously over long distances through telephone lines, microwaves, and satellites; broadcast stations reach their audiences over the airwaves; and cable systems distribute through coaxial cables. (As noted above, the promise of cable among critics of broadcast television stems largely from the difference in technology.)

Viewed as communication systems rather than industries, the primary function of these media is to circulate ideas (content analysis). These ideas have consequences for every aspect of the social process (effect analysis). The circulation of ideas is an evolutionary process: From the enormous variety of possibilities in society, some ideas are introduced into the system; some are developed or otherwise modified as they circulate through the system; and some are deleted from the system. The conventional descriptions of the participants are an incomplete guide to the multiple functions of each. Writers do introduce ideas but so do producers and directors, networks and advertisers, and local outlets. Public officials may introduce ideas when they give speeches, hold press conferences, hearings, or otherwise generate enough interest to attract coverage. Members of the public who normally serve as audiences may also introduce ideas when placed before microphones and cameras in the studio or on the streets-as in the case of television coverage of the 1965 riots in Watts. Similarly, any participant modifies an idea to the extent that the understanding he passes along differs from the understanding of his source; and everyone now and then avoids exposure to an idea (or the person exposing it) and neglects or refuses to propagate some of the ideas that have come to his attention. Moreover, conven-

\footnotetext{
20 Harold D. Lasswell "The Structure and Function of Communication in Society," in Wilbur Schramm, ed., Mass Communications (Urbana: University of Illinois Press, 1960), pp. 117-130.
} 
tional descriptions of programs by categories are an incomplete guide to the multiple effects of the ideas contained in each. ${ }^{21}$ As we have seen news and public affairs programs may entertain, and entertainment programs may educate and inform. ${ }^{22}$ Furthermore, a given idea often can be dramatized, presented as news or news analysis, or exemplified in coverage of a sports event..$^{23}$

The flow of ideas depends upon the actions of each participant, and the action of each participant depends upon how he perceives his net advantage. ${ }^{24}$ This perception selectively takes into account the resources of various kinds at his disposal, the obstacles and opportunities afforded by the structure of the system, and the expected actions and reactions of others.

Of course a participant may be mistaken, in retrospect, about the outcomes he prefers and about the expected consequences of his actions; and some actions are deliberate while others are undertaken with little deliberate thought. A change in any factor in the system may change the perceived interests of a participant and therefore the behavior of the participant. The result may be to exacerbate or ameliorate one or more of the multiple barriers to diversity in the system, or to leave them in place. In short, diversity is contextual: For research and policy purposes, judgments about the priority of any particular barrier to diversity depend upon an understanding of the structure and functioning of the system as a whole.

\section{Commercial Broadcast Television}

Criticisms of commercial broadcast television can be reviewed to illustrate the application of this contextual conception of diversity. The basic allegation is that free speech is subordinated to profitable speech ${ }^{25}$ by networks, acting as agents of advertisers, and by broadcasters in general. The trade-off between free speech and profitable speech is rooted in economic considerations. Program revenues are directly proportional to the size of the audience a program can attract. At a given level of program quality (in a technical sense), program costs are insensitive to audience size. Program content is therefore adapted to attracting the largest possible audience (or at least the largest affluent audience, for which an advertiser might pay more per viewer). However valuable or important an idea might be to a small audience it tends to be deleted in favor of an idea that might attract a large audience. Similarly, a controversial idea expected to gratify part of a national audience but to offend another

\footnotetext{
21 Compare Bruce Owen, "Diversity and Television" (Office of Telecommunications Policy, Staff Research Paper Series, August, 1972), pp. 6-7: "In the context of the policy discussions, diversity is generally taken to mean the number of programs of different 'kinds'." The assumption that entertainment programs only entertain (for example) is an important element in Owen's contention that "diversity" is largely irrelevent to freedom of expression.

22 Cf. William E. Hocking, as quoted in Ashbrook P. Bryant, "Historical and Social Aspects of Concentration of Program Control in Television," Law and Contemporary Problems, 34 (1969), p. 611. "The motive of the consumer is described in terms of 'entertainment' and 'information'; it is seldom that he deliberately seeks 'education' there. (But) an unintended education takes place, perhaps the more effective because unintended ....".

${ }^{23}$ For example, the idea expressed by the late football coach, Vince Lombardi: "Winning is not the only thing, it's everything."

24 See Lasswell's outline of the maximization postulate in A Pre-View of Policy Sciences, pp. $15 \mathrm{f}$.

25 Johnson, op. cit., p. 74.
} 
part tends to be deleted in favor of less controversial fare. Thus profits are maximized, and the advocates of specialized or controversial ideas are not heard. Over the long run, technology and organizational practices in the medium are adapted to commercial interests.

A number of factors contribute to the networks' control of program creation and production. With options on the broadcast time of large numbers of stations, they enjoy a virtual monopoly over access to the largest national audiences. This advantage is compounded by financial and contractual arrangements. While networks have the resources to finance their own programs, independent producers often do not. Banks and conventional lending institutions are normally unwilling to assume the risks of financing program development. In these circumstances the independent producer seeks at least partial network financing. In exchange, he concedes to the network a portion of the program's eventual revenues and "the right to participate in the creative process to the extent necessary to assure themselves (the network) and mass advertisers that the program or series will be initially designed to attract large circulation and that subsequent episodes of a series will adhere to the 'formula' originally designed." 26 In the step-by-step arrangement normally used, the network finances each step of production separately and retains the right to discontinue financing at any step. This is an effective means of enforcing conformance to restrictions originally imposed in the program licensing contract. ${ }^{27}$ The independent producer submits as a necessary condition of practicing his craft. No one else can or will offer him financing or a large enough audience to recover his projected costs.

The advertisers' interests in program creation and production largely coincide with the networks'. Having learned in radio that the advertiser bore the brunt of public reactions to unpopular or controversial ideas, the advertising agencies gained a voice in program production and have retained it in network television. ${ }^{28}$ The interests of the affiliated local stations also largely coincide with the networks', but in a different way. The affiliated stations can and sometimes do refuse to "clear" a network program, but typically they do not. Network programs relieve the station of the effort and expense of producing its own programs, and is sufficiently profitable. Moreover, effective mass appeal programs normally are too expensive for local stations to undertake on their own. ${ }^{29}$

By some accounts the current pattern of control stems from the limited capacity of the frequency spectrum: It is insufficient to accommodate all those who might

26 Bryant, op. cit., p. 626.

27 Bryant, ibid., quotes the CBS Annual Report to Stockholders (1963), p. 12, adding his own emphasis: "The ability to produce a program schedule which year after year commands the largest audience in broadcasting is founded on a steadfast commitment to two fundamental programming principles. The first is to obtain the talents of those writers, producers, directors and performers whose outstanding abilities and dedication permit no compromise with anything less than their best efforts at all times. The second is the continuing participation of the Network's programming officials at every stage of the creative process from the initial script to the final broadcast. This applies not only to the occasional special program, but to the day-to-day production of continuing program series."

28 Ibid., p. 621.

29 A report in the Wall Street Journal (May 26, 1977), p. 1, notes that WCVB of Boston "is the only individual station that produces shows with syndication, as well as local consumption in mind. Because it takes money to produce a show and time and trouble to sell one, stations generally shun a syndicating role." 
wish to use the medium. This gave rise to the initial attempts of Herbert Hoover, then Secretary of Commerce, to license radio broadcasters and, eventually, to the Radio Act of 1927. The current pattern has also been traced to the discovery, almost by accident, that advertising was a viable foundation for the development of the new medium; and to the technical feasibility of interconnection among radio stations nationwide. ${ }^{30}$ Whatever the potential for concentration of control inherent in these historical circumstances, they are not sufficient conditions to account for the current situation and they were not fully and immediately exploited. As late as the 1955-56 season, approximately half of the entertainment programs on the schedules of the two largest networks were approved by the networks in their original form, subject only to standards of taste, decency, and the like. ${ }^{31}$ Moreover, UHF channels have become available even if not widely used.

The other participants adapt as well as they can. Smaller audiences that share a special or controversial idea have no voice to the extent that special or controversial viewpoints of potential appeal to them are censored out of the system in program creation and production. All audiences, large and small, are left with the option of viewing what has survived production, network distribution and local clearance, or of not viewing. If the latter option is taken in sufficient numbers, the audience through audience rating services has a voice in deleting programs and ideas from the system. The government has authority to regulate those licensed to use the airways owned by the public. But the current situation has evolved under the regulatory and statutory framework, and attempts to reduce concentrations of control have not given expression to specialized or controversial viewpoints within the public. For example, in order to free broadcast time from network control and encourage independent production, the F.C.C. imposed a prime time access rule. The local stations found it profitable to fill the time with mass-appeal game shows, and independent producers adapted to the demand. With the public so dependent on television for "entertainment" and "information," a prudent politician approaches the regulation of broadcast television with caution.

An account so brief as this necessarily passes over variations on the basic pattern and other complexities in the system. But it does illustrate how the concept of diversity can be implemented to clarify research and policy priorities. Suppose that the following tentative conclusions are warranted in the light of a detailed examination of available evidence: First, the trend in commercial broadcast television increasingly has been to subordinate the general interest in free speech to profitable speech. Second, the trend can be traced directly to the commercial interests of broadcasters and indirectly to a host of other factors that maintain their position of control. Stated another way, they have been able to adapt the functioning and structure of the medium to their own commercial interests. Self-regulation has not arrested the trend. Third, in the absence of policy changes by other interests, the projection is that the basic trend will continue into the future, subject only to modification in details. Under these circumstances, additional diagnoses of the problem would be less important than prescriptions to deal with it. The top priority

\footnotetext{
${ }^{30}$ Bryant, op. cit., pp. 613-617 contains a section on "Early History."

31 Ibid., p. 623.
} 
would be the invention, evaluation and selection of policy alternatives. For example, what factors might be changed by public or private policy to induce those in control to adapt program content to the diverse, changing interests of smaller audiences, as a means of serving the existing commercial interests? What public or private policies might disperse control over the introduction of ideas into the system? The evaluation of any alternative would entail the reexamination of existing research (and possibly the execution of new research) on trends, conditions, and projections in order to estimate the probable impact on diversity. ${ }^{32}$

\section{Cable Television}

The promise of cable as a supplement or alternative to broadcast television is largely technological. By propagating electromagnetic waves through a coaxial cable, it is feasible to transmit $\mathbf{4 0}$ to 100 programs simultaneously from the headend of a cable system into individual homes. It is also feasible to transmit a signal from individual homes "upstream" to the headend of a system. With the use of encoders (scramblers) and decoders, regular cable service consisting primarily of improved reception of marginal broadcast signals can be supplemented by pay-cable service. In the latter, a subscriber pays a per-program or per-channel fee for cable-originated programs, in addition to the monthly fee for regular service. With the use of much more sophisticated devices, the home television set can become the display unit of a home information processing system linked by cable to a central computer.

Until several years ago it was sometimes assumed that the technically possible in cable was virtually inevitable. Society needed a supplement or alternative to broadcast television, as well as new communication services; hence the technical possibilities would be realized. Moreover, it was sometimes assumed that changes in how signals were distributed would give rise to changes in who said what to whom, with different social effects. A large number of channels was not only possible; they would be built and they would be programmed by different commercial interests and by non-commercial interests. A two-way capability would be installed, permitting the audience to talk back and permitting the audience to assert more control by paying only for individual programs (as opposed to the per-channel package selected by someone else). In addition, the monthly subscriber fee for regular cable service, and particularly the additional fee for pay-cable service, would provide an alternative financial foundation for the medium. Advertiser influence would be reduced in the cable-originations covered by the regular subscription fee, and eliminated by F.C.C. regulation in pay-cable originations. Since revenues per viewer would be much higher in pay-cable than in broadcast television, programs of high technical quality could be produced for smaller audiences. For example, if the rate per viewer were 50 or 100 times higher than the few cents per viewer an advertiser is willing to pay, then the audience could be 50 or 100 times smaller without decreasing total revenues. In short, optimistic expectations about the future of cable were grounded in the

\footnotetext{
32 The five tasks referred to in an earlier footnote "imply principles of content and procedure. As guides to content, they are reminders of questions worth raising in the consideration of any problem. As principles of procedure, they imply the wisdom of performing the various tasks in an orderly manner." Lasswell, A Pre-View of Policy Sciences, p. 39 (Emphasis in the original).
} 
technical possibilities and extrapolated in the direction of idealized preferences by some critics of broadcast television.

These optimistic expectations have been undermined in recent years. By September, 1976 only $23 \%$ of the nation's 3,715 cable systems had more than 12 channels..$^{33}$ Two-way channels were extremely rare. Thirty-five percent of the cable systems did not originate programs at all, but simply relayed broadcast television signals. Another $37 \%$ provided only automatic originations such as time and weather or a stock market ticker. The remainder provided some non-automatic originations such as live local programs, syndicated television re-runs or rejects, or tapes prepared for a public access channel. These originations continue to be marginal in many respects, including audience attractiveness and large amounts of unprogrammed time. The major exception is pay-cable.

Home Box Office, a Manhattan-based subsidiary of Time, Inc., became the first operating pay-cable network in November, $1972 . .^{34}$ It of fered a monthly package of programs, primarily recent movies and sports events, to cable system operators who were willing to invest in a decoder to be installed in subscribers' homes. The cable operator sold the service to his subscribers for a per-channel monthly fee, which he split with Home Box Office. Since the beginning of operations, Home Box Office has expanded from regional microwave distributions to nationwide satellite distribution; and it has contracted with large MSO's to provide pay-cable service. The largest of these is Teleprompter, with over 1.1 million subscribers. By March, 1977 Home Box Office claimed over 600,000 subscribers in more than 300 cable systems nationwide, ${ }^{35}$ and had already announced that it would eventually open a second network. Optical Systems, based in Los Angeles, is the nearest competitor, a distant second in terms of subscribers.

An important factor in the growth of pay-cable and particularly Home Box Office is that both the network and the cable system operator have an incentive to add subscribers, since revenues rise faster than costs. Moreover, the cost to deliver perchannel service to a home is considerably less than the cost to deliver per-program service; and satellites have reduced the cost of nationwide distribution to the point that it becomes economically feasible. Home Box Office began operations with perchannel service, and was the first pay-cable network to begin satellite distribution, backed by the financial muscle of Time, Inc. It also took care to nurture a competitive advantage in "software." On the one hand, it gained the expertise and good will necessary to ensure a supply of good programs, particularly movies. This may turn out to be particularly important, since "The biggest obstacle in pay television's way is a shortage of movies." ${ }^{36}$ Time has invested $\$ 5$ million in the making of 20 feature films by Columbia Pictures, a move that has been linked with the need to insure a supply. ${ }^{37}$ On the other hand, Home Box Office has considerable marketing experience and has access to cable systems serving lucrative markets. Optical Systems

33 These percentages have been calculated from statistics in Television Factbook, op. cit., pp. 73-a, 75-a.

${ }^{34}$ Reviews of recent developments can be found in "Pay Television in America: Feevee's Charge" The Economist (September 27, 1975), pp. 76-79; and "Movies at Home via Satellite," The Economist (September 25, 1976), p. 123.

36 "Movies at Home Via Satellite," op. cit., p. 123.

35 Broadcasting (March 28, 1977), p. 95.

37 Ibid. 
has recently complained to the F.C.C. that cable operators are stifling competition by denying access. ${ }^{38}$ Growth among the leading networks changes the competitive situation for the other networks. In short, there are tentative grounds for the pessimistic expectation that the newer medium is in transition toward a structure dominated by one or possibly two networks; and that under these circumstances, free speech might once again be subordinated to profitable speech, and for many of the same reasons.

Much less is known about the circulation of ideas through cable television than broadcast television and the problem is compounded by relatively rapid changes in the newer medium. Both the optimistic and pessimistic expectations are based on simplified and to some extent selective treatments of the limited base of information. Thus more systematic observation and analysis are needed. Given a preference for diversity, the top priority might turn out to be an analysis of trends in control over program content. Who introduces, shapes, and deletes ideas in the system? Which interests are served? By what techniques of control? This might lead to an analysis of conditioning factors, and eventually to the projection of future contingencies. A realistic and contextual diagnosis of potential problems is a first step in the design of possible solutions. ${ }^{39}$

\section{Conclusions}

Tradition, law and contemporary experience leave little doubt that the overriding preference in our society is for a free flow of ideas in the media of mass communications, including television. Diversity as a policy goal is appropriately understood in these terms. The task is to implement the goal in present circumstances. This requires models of sufficient comprehensiveness to guide the search for barriers to diversity and to invent, evaluate, and select policy alternatives in each case. The setting of priorities in the task of implementation has been illustrated using available studies of broadcast and cable television. Partial concepts of diversity that now dominate public discussion are a handicap in defining priorities for the necessary communications policy research.

The problem goes beyond policy research to other phases of the policy process. Partial concepts of diversity are conveniently picked up by organized interests and used to promote their special claims in public hearings and debates. The principal effects of these partial concepts are twofold: First, they divert attention from the broader context in which competing claims can be productively compared and evaluated, and in which unorganized, common interests can be discovered and heard. Second, they help to reinforce the existing structure of control over communications policy. A detailed account of these relationships has yet to be written. When it is, social scientists may discover that they have contributed to the problem rather than the solution. Good intentions and specialized training in one of the policy-relevant disciplines are no guarantee of a responsible and constructive role in the policy process.

\footnotetext{
38 Broadcasting (January 31, 1977), pp. 57-58.

39 Again, the point is to consider all five tasks, and to establish and revise priorities among them as the analysis unfolds.
} 